\title{
Cincinnati's SWMM Model: A Journey Through Time
}

\author{
Uzair (Sam) Shamsi, ${ }^{1}$ Ben Gamble ${ }^{2}$ and Joe Koran ${ }^{2}$ \\ ${ }^{1}$ Jacobs Inc., Pittsburgh, Pennsylvania; ${ }^{2}$ Metropolitan Sewer District of Greater Cincinnati, Cincinnati, Ohio.
}

\begin{abstract}
The Metropolitan Sewer District of Greater Cincinnati's (MSD) SWMM model is one of the largest SWMM models in the world. In developing this model, MSD advanced the state-of-the-art in collection system modeling in a number of areas including the size and scope of the model, the application of radar rainfall data, the use of water consumption data to estimate dry weather flows, and the use of GIS for model development. It provided MSD with an extraordinary tool to evaluate existing and projected conditions and to use a modeled problem with a modeled solution approach for consent decree compliance. This paper provides the history, features and applications of the MSD SWMM model. Modeling challenges and lessons learned are also discussed.
\end{abstract}

\section{Introduction}

MSD (The Metropolitan Sewer District of Greater Cincinnati) provides sewerage collection and treatment services to approximately 230000 residential and commercial and 250 industrial users in Hamilton County, Ohio. It serves a population of about 855000 in an area covering $290 \mathrm{mi}^{2}\left(751 \mathrm{~km}^{2}\right)$ through $\sim 3000 \mathrm{mi}(4828 \mathrm{~km})$ sanitary and combined sewers. The system includes seven major wastewater treatment plants treating 70000 MG/y ( 264978 $\mathrm{ML} / \mathrm{y})$, three package treatment plants, $>120$ pump stations, and five real time control (RTC) facilities. The treatment system has a dry weather capacity of 200 MGD (757 ML/d). The largest Mill Creek plant has a wet weather capacity of 440 MGD (1 665 ML/d). Figure 1 shows the MSD sewer system and seven sewage treatment plants and corresponding tributary areas (basins).

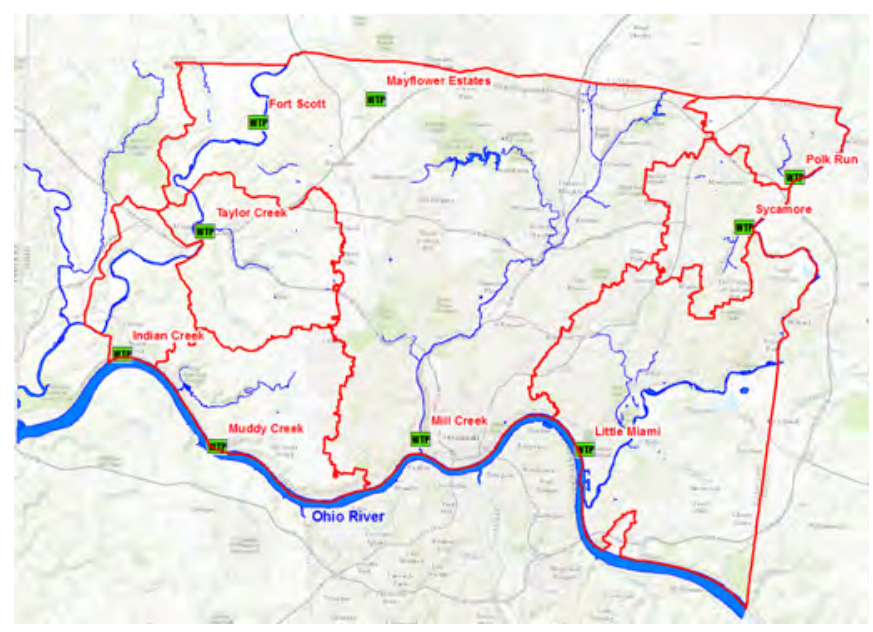

Figure 1 MSD service area showing seven sewage treatment plants and basins.

\subsection{Consent Decree}

In the late 1980s and 1990s, the United States federal government, through the Clean Water Act, called for the elimination of sanitary sewer overflows (SSOs) and a reduction of discharges from combined sewer overflows (CSOs). This action affected every wastewater system in the country, including the MSD. Increased scrutiny from the U.S. Department of Justice (DOJ) and U.S. Environmental Protection Agency (USEPA) brought the issue to the forefront in the late 1990s as these government bodies began enforcing the Act in large cities and levelling heavy civil penalties on those out of compliance. In 1999, MSD, which had already begun addressing the elimination of its SSOs and reducing CSOs, entered into negotiations with the USEPA, DOJ and the State of Ohio to establish a formal remediation program that would be recognized and supported by the government, and which was also affordable for local ratepayers. The resulting agreement is called the Consent Decree. The remediation of CSOs, SSOs and basement backups are key components of the Global Consent Decree which was filed in 2003.

Compliance with the consent decree is based upon a modeled problem with a modeled solution approach which means that both the problem identification and the recommended solutions (projects) are based on a model. The consent decree requires completion of 116 Phase 1 projects totalling $\$ 1.14$ billion by December 2018. As of October 2014, 96 of these projects have been completed and the remaining ones are expected to be completed on time. In addition, >260 Phase 2 projects totalling $\$ 2$ billion should start in 2019. The MSD website (msdgc.org/msdcip/cips/ index.html) provides an interactive online map, shown in Figure 2 , to search and display construction projects in various communities. The map includes the following two project types.

Shamsi, U.M., B. Gamble and J. Koran. 2016. "Cincinnati's SWMM Model: A Journey Through Time." Journal of Water Management Modeling C398. doi: 10.14796/JWMM.C398.

(c) CHI 2016 www.chijournal.org ISSN: 2292-6062 
WWIP (Wet Weather Improvement Plan)

WWIP projects are required under MSD's consent decree to reduce CSOs and eliminate SSOs. They include Phase 1 projects to be completed by 2018 (listed as Active or Completed) and Phase 2 projects to be completed after 2018 (listed as Active or Future).

\section{ASSET (Asset Management)}

Asset management projects are not required by the consent decree but are necessary to rebuild MSD's aging sewer system. These projects are prioritized each year based on criteria such as the condition of the sewer or other equipment and operating efficiency.

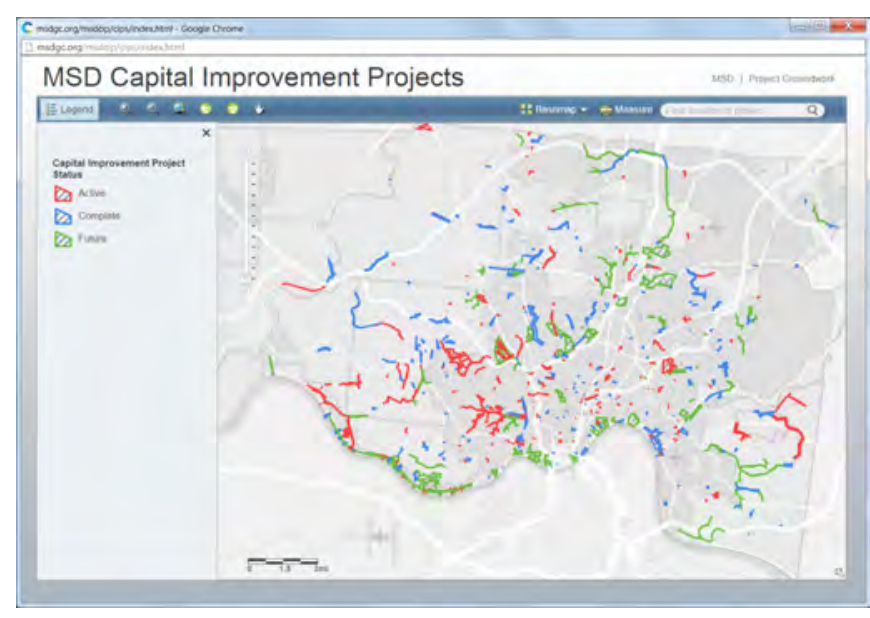

Figure 2 Interactive online map for consent decree projects.

\section{Model History}

Cincinnati's first storm sewer was constructed in 1828. During 1856-7, Mark Twain worked in Cincinnati in a printing shop. He probably didn't say, "If the world comes to an end, I want to be in Cincinnati. Everything there comes ten years later." Fortunately, this does not apply to modeling in Cincinnati, which started much sooner than elsewhere. MSD was established in 1968. Figure 3 shows the model development timeline from 1975 to 2003. MSD's first SWMM model was developed in 1975 using USEPA's SWMM version 2. Though it did not include all the seven basins, developing that model using punched cards was not an easy task. In 1995, a living model was developed for the 1991 Stormwater/Wastewater Integrated Management (SWIM) master plan. The model name reflected the enthusiasm of MSD staff and management.

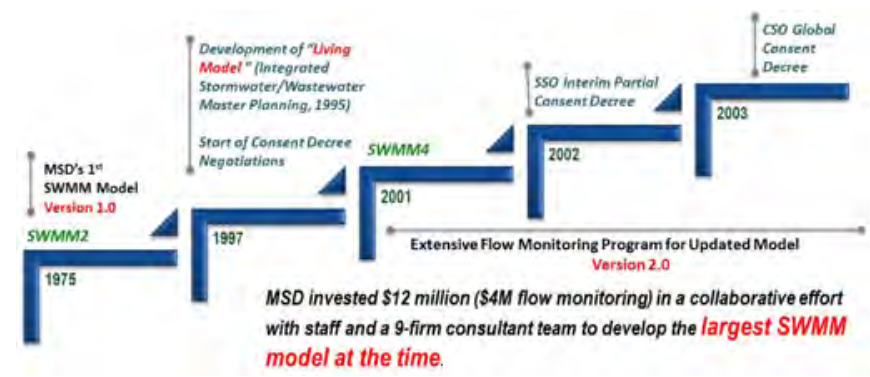

Figure 3 Modeling timeline 1975-2003.
During the period 2001-2003, MSD developed its model version 2, a calibrated and validated hydrologic and hydraulic model of the sewer system using USEPA's SWMM4 modeling software (Huber and Dickinson 1988; Roesner et al. 1988). This comprehensive $\$ 12$ million modeling ( $\$ 8$ million) and monitoring ( $\$ 4$ million) project was completed jointly by MSD and a nine-firm consultant team (CDM 2003). Referred to as the System Wide Model (SWM), with 42206 nodes and 26629 subcatchments in 7 basins, this was at the time one of the largest models of its kind ever constructed. SWM was calibrated and validated using at least 4 months of data from 300 flow monitors. At least 3 storms from the flow monitoring data were selected for the model calibration and validation (C\&V, CDM 2003). With advanced features such as RTC modeling and continuous simulation, the model provided MSD with an extraordinary tool to evaluate existing and projected conditions within the sewer system. Due to the sheer size of the model and the computational speed available at the time, long term continuous simulations to produce CSO statistics were run using the kinematic wave solution to overcome long run times.

Since 2003 both modeling software and computing speed have significantly advanced, and MSD has consistently added detail and upgraded the model. In 2004, SWMM5, the first Windows version of SWMM with a graphical user interface (GUI), was released by USEPA (Rossman et al. 2004). By 2006, MSD had converted its SWMM4 model to a fully calibrated and validated dynamic wave SWMM5 model. Referred to as SWM Version 3, this model served as the baseline condition model for planning consent decree projects. The physical characterization of the collection system has been improved through field investigations of the system and modifications in the way in which regulators are represented, amongst other changes. Model calibration and validation has been supported through a monitoring program that has gathered a substantially increased amount of flow data both in the number of locations monitored and the duration of monitoring. With over 28000 nodes and 6550 subcatchments, the Mill Creek sub-model is the largest SWM model. It takes $\sim 7 \mathrm{~d}$ to run the typical year simulation at a $30 \mathrm{~s}$ routing time step using SWWM 5.0.021 on a 2013 Dell desktop computer (4 cores, 3.2 $\mathrm{GHz}$, Windows 7 Professional). Model run time was reduced by $35 \%$ by running the model on an 8 core computer using the new PCSWMM parallelized OpenSWMM engine 5.1.907, released in February 2015 and based on USEPA SWMM version 5.1.007. However, the model results were slightly different.

In 2010, the $\$ 3.2$ billion Wet Weather Improvement Plan (WWIP) required by the consent decree was approved. In 2011, the first version of MSD Modeling Guidelines and Standards was published. The current 2013 Version 3 is the latest version of modeling guidelines (MSD 2013). In 2014, SWM version 4.3 representing calibrated and validated updates for the Lower Mill Creek partial remedy (LMCPR) were approved by the regulators-an important milestone in MSD's modeling history. 


\section{Modeling Innovations}

In developing the SWM, MSD advanced the state of the art in collection system modeling in a number of areas, including the size and scope of the model, GIS applications for model development, the application of radar rainfall data, and the use of water consumption data to estimate dry weather flows.

\subsection{Model Detail and Resolution}

The level of detail incorporated into the model equals or exceeds that of many models developed for similar applications (i.e. large metropolitan areas under CSO/SSO consent decrees). With $>51000$ nodes in the current version, MSD's SWM continues to be one of the largest SWMM models. Table 1 summarizes the current model. Figure 4 shows model sewers, combined sewer areas and CSO outfalls.

Table 1 System Wide Model summary.

\begin{tabular}{|c|c|}
\hline Model Object & Count \\
\hline Nodes & 50173 \\
\hline Subcatchments & 30574 \\
\hline Sewers & 50689 (1900 miles) \\
\hline Outfall nodes & 200 \\
\hline Weir Links & 243 \\
\hline Orifice Links & 1690 \\
\hline Pump Curves & 80 \\
\hline Rain Gauges & 35 \\
\hline
\end{tabular}

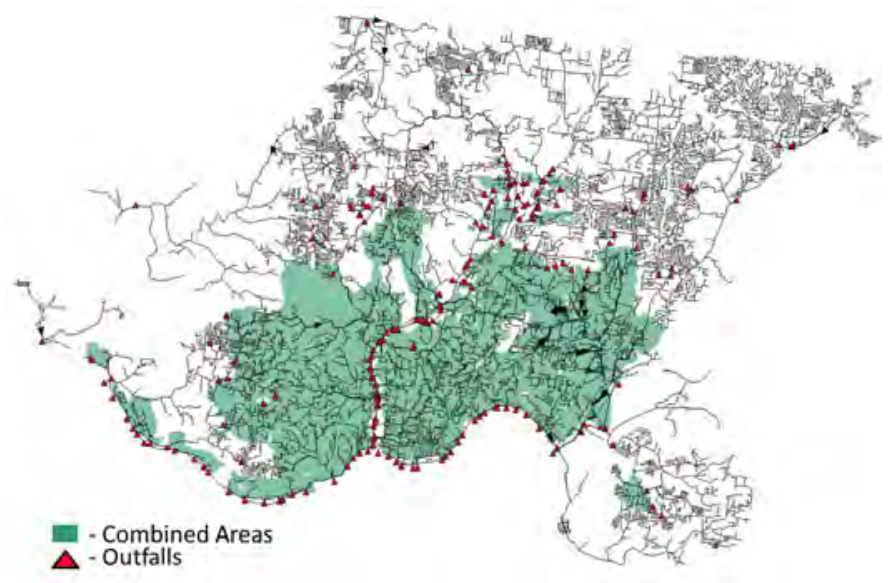

Figure 4 SWM sewers, combined sewer areas, and CSO outfalls.

As shown in Table 1, the model has a very large number of model objects (subcatchments, manholes, sewer pipes, pumps, regulators, outfalls). As shown in Figure 5, the model has a large number of subcatchments to accurately depict the hydrology of drainage areas. Approximately $50 \%$ to $60 \%$ of sewers from GIS have been included in the model. The model includes 3 in. $(7.62 \mathrm{~cm})$ to $20 \mathrm{ft}(6.1 \mathrm{~m})$ collection system sewers at street level resolution, which is essential to build accurate physical models. Compared to less accurate and approximate lumped models, such physical models are also suitable for green infrastructure modeling.

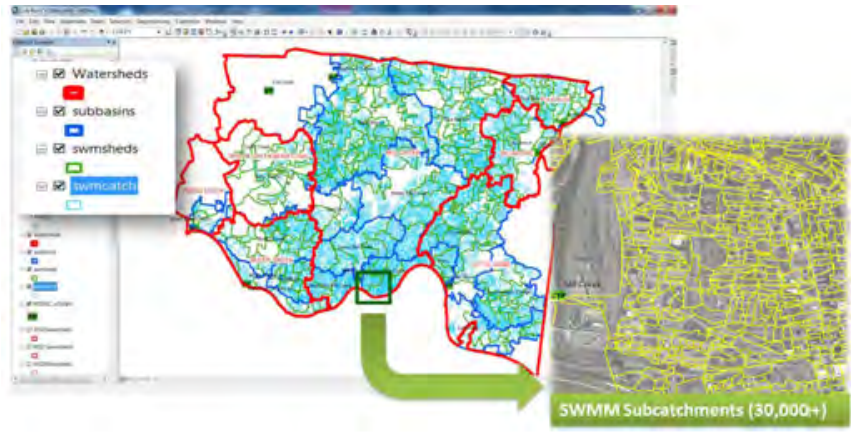

Figure 5 SWM subcatchments.

\subsection{CAGIS}

Started in 1986, Cincinnati Area Geographic Information System (CAGIS) is an enterprise wide consortium that provides Cincinnati and Hamilton County government agencies and private utilities with access to GIS data. It serves more than 1000 employees of these agencies, including front counter staff, managers, plan examiners, and planning, engineering, accounting, dispatch and field crews. CAGIS Online is a powerful Web mapping site that provides public access to key GIS data. It enables users to create sophisticated maps tailored to their own needs and to query the underlying GIS data. The site includes street, topography and property based maps, along with aerial photographs dating from 1996 to 2011. Additional GIS layers can be added to these base maps, and users can add their own labels, graphics and comments. Reporting tools identify a wide array of information, including property ownership, jurisdiction, zoning, land development, sale date and amount, and deed number (Hamilton County 2015).

Modeled sewer network data was derived using CAGIS as the primary data source. Figure 6 shows the sewer network in CAGIS.

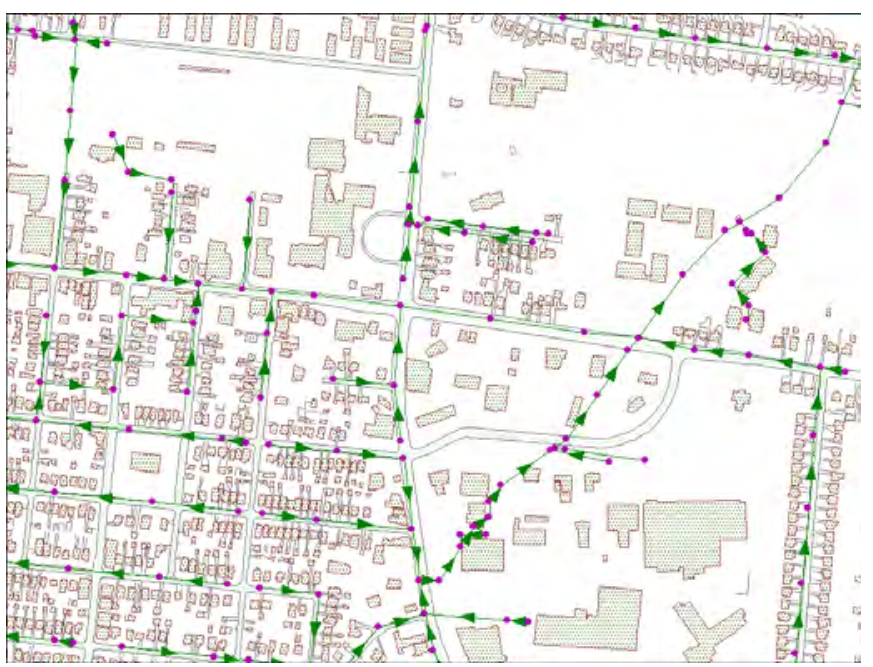

Figure 6 Sewer network in CAGIS. 
Direct transfer of the digital files defining the network elements (individual database records with unique identifiers), spatial data (topology, $x-y$ coordinates and invert elevations for each record) and attribute data (pipe diameters, plan lengths and pipe material for each record) was made between the project office computer network and the CAGIS network. The CAGIS data files were queried and the combined sewers of diameter $\geq 18 \mathrm{in}$. $(45.7 \mathrm{~cm})$ and sanitary sewers of diameter $\geq 12 \mathrm{in}$. (30.5 cm), along with the associated manholes, were extracted from the CAGIS data tables. These sewers and manholes were stored in separate shapefiles and Microsoft Access database.

\subsection{Radar Rainfall Data}

Precipitation data provided the basic time variable input to the SWM, and therefore the precision, accuracy, and resolution of these data are of critical importance to the project. Inadequate precipitation data introduces calibration errors, or misrepresents model input, which in turn reduces model accuracy and reliability for simulation of the sewer system.

At the time of SWM development, MSD operated 35 rain gauges throughout its service area. The rainfall data collected at these locations provides good measurements of rainfall at the point of collection. These measurements, however, do not define the actual rainfall characteristics between the rain gauge locations due to the spatial variability of the rainfall. Accounting for the rainfall spatial variability was important for developing accurate models; thus the project team applied the state of the art radar rainfall technology to derive rainfall data between gauges and obtain subcatchment specific rainfall data to support model C\&V. The radar measurements collected using the National Weather Service's (NWS) NEXRAD (NEXt generation RADar) were calibrated using rain gauge measurements. Radar-rain data was obtained for 56 different rainfall events that occurred during the flow monitoring program. The 56 rainfall events were carefully selected by the SWM project team in order to support two primary purposes:

1. Characterization of the RDII response throughout the study area; and

2. Support model C\&V.

\subsection{Dry Weather Flow Estimation}

The SWM project team investigated water use data capture and transfer procedures with Cincinnati Water Works staff, and with other water supply jurisdictions within the service area. Water billing records were then obtained for the entire service area for the winter months over $4 \mathrm{y}$. Each customer address in the water consumption database was geocoded using the CAGIS street layer, which allowed the water customers to be correlated to the modeled subcatchments by incorporating them into the drainage basin basemap. The dry weather flow model input was then generated for each catchment area with database queries to obtain average winter water consumption.

\section{Challenges, Solutions and Lessons}

\subsection{Model Recalibration and Revalidation}

All models are an approximation of reality and there is no such thing as a perfect model. George Edward Pelham Box (1919/10/18-2013/03/28) was a British mathematician and profes-sor of statistics at the University of Wisconsin, and a pioneer in the areas of quality control, time series analysis, design of experi-ments and Bayesian inference (Wikiquote 2015). Box's famous quote "Remember that all models are wrong; the practical ques-tion is how wrong do they have to be to not be useful" suggests a reasonable alternative to rigid $C \& V$ standards devoid of engineer-ing judgment (Box and Draper 1987; James 2005).

Whether a model may or may not be considered sufficiently calibrated should depend in part on the intended use of the model (e.g. planning or operation). There is no standard for the adequacy of calibration. For some users a $25 \%$ accuracy is adequate while others insist on $10 \%$. Calibration and validation cost money, and are the most painful phase of any modeling project. Also, the cost of collecting calibration data is substantial, perhaps more than the modeling (James 2005).

As described previously, the SWM was calibrated and validated during 2001-2003 using an extensive flow monitoring program. Unfortunately, MSD's 2011 modeling guidelines (MSD 2013) suggested model $C \& V$ criteria which were different from the 2001-2003 model C\&V criteria. The 2011 criteria were based on rigid and event based standards from the United Kingdom's Wastewater Planning Users Group (WaPUG, WaPUG 2002). This difference in the model C\&V criteria necessitated another round of model recalibration and revalidation. Substantial flow monitoring and model recalibration and revalidation has been conducted since 2011, but many sewersheds do not appear to meet the WaPUG model C\&V standards, which has resulted in frustration and delays in moving some consent decree projects to design and construction stages. WaPUG event based standards neglect small-er storm events which generally create most of the CSO volume, and therefore are not suitable for continuous simulation. WaPUG is expected to revise their model C\&V standards for continuous simulation. MSD is also revising their modeling guidelines to use alternative $C \& V$ methods, such as those based on statistical good-ness of fit measures. The integral square error (ISE) implemented in PCSWMM seems promising (Marsalek et al. 1975; James 2005).

\subsection{Model Status}

Because of numerous concurrent flow monitoring and model recalibration and revalidation projects, it has been challenging to track the current model C\&V status of hundreds of sewersheds. To prevent repeated flow monitoring and model $C \& V$ projects for the same area, model $C \& V$ should not be perceived as a model pass or fail test. To avoid unnecessary project expenses and delays, model C\&V status can be quantified rather than labelled simply as uncalibrated or invalidated. 
A fallacy of event based calibration of a sewershed is that all metersheds of the sewershed are judged the same way (i.e. given the same weight) regardless of their size. For example, the entire sewershed model can be labelled as uncalibrated even if a small metershed covering only $1 \%$ of the sewershed area misses the C\&V criteria slightly. To address this issue, GIS can be used to calculate the percentage of the sewershed area calibrated and validated. This method will give a higher priority to large calibrated and validated metersheds with capital projects than small metersheds without any planned projects which do not completely meet the C\&V criteria. This method allows quantification of sewershed C\&V status. Metershed models can then be approved for various modeling applications based on their C\&V status using the model application criteria presented in Table 2.

Table 2 Model application criteria.

\begin{tabular}{lccc}
\hline Metershed Calibration and Validation Status & Planning & Preliminary Design & Final design \\
\hline Calibrated and validated & Yes & Yes & Yes \\
Calibrated and partially validated & Yes & Yes & No \\
Partially calibrated and validated & Yes & Yes & No \\
Calibrated (not validated) & Yes & Yes & No \\
Validated (not calibrated) & Yes & Yes & No \\
Partially calibrated & Yes & No & No \\
Not calibrated and validated & No & No & No \\
\hline
\end{tabular}

MSD is implementing GIS based model C\&V status dashboards developed by the primary author to document which areas of the city are calibrated and validated and can move to final design stage. Figure 7 (preliminary results) shows the Lick Run sewershed C\&V dashboard map with 11 metersheds. Green areas (9 metersheds covering 95\% sewershed area) represent calibrated and validated metersheds suitable for planning, preliminary design, and final design. Pink areas (one metershed covering $4.3 \%$ basin area) represent calibrated (but not validated) metersheds suitable for planning and preliminary design. Yellow areas (one metershed covering $0.7 \%$ basin area) represent partially calibrated metersheds suitable for planning applications only.

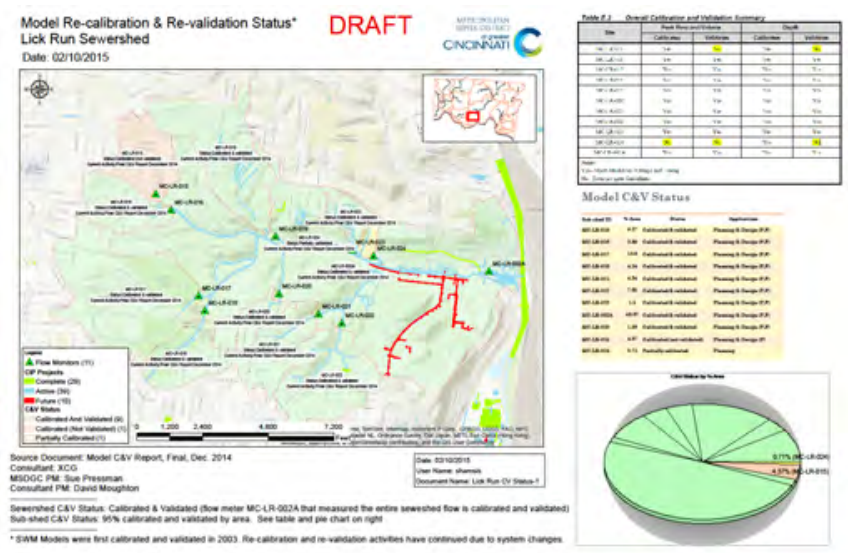

Figure 7 Lick Run model C\&V dashboard.

\subsection{Model Evaluation}

Essentially the following four major components of data are necessary for model C\&V:

1. Subcatchment physical properties (for hydrology);

2. Sewer system geometry and attributes (for hydraulics);

3. Rainfall data; and

4. Flow monitoring data.

All are necessary for proper model C\&V and all should be evaluated to assess the accuracy of a model. PCSWMM's automatic engineering audit and attribute validation tools can be used to evaluate the first two components. Often, evaluation of some of these components is neglected because the entire focus is on meeting the model C\&V criteria. Excessive focus on model $C \& V$ can result in fully calibrated and validated but physically inaccurate black box models which can simulate the flow monitoring period perfectly, but fail terribly in other years or in seasons with different climate and soil conditions. Similarly, model output is often evaluated using continuity errors alone while neglecting other important factors such as model instability, run time and dry pipes. These issues and model C\&V challenges described above encouraged the primary author to develop model report cards based on a holistic and balanced model evaluation approach rather than one solely focused on the model C\&V status.

A model report card is an objective and quantitative measure of a model's efficacy rather than an arbitrary and subjective assessment. Figure 8 (preliminary results) shows an example report card for the Bloody Run sewershed submodel with an outstanding grade point average (GPA) of 3.9.

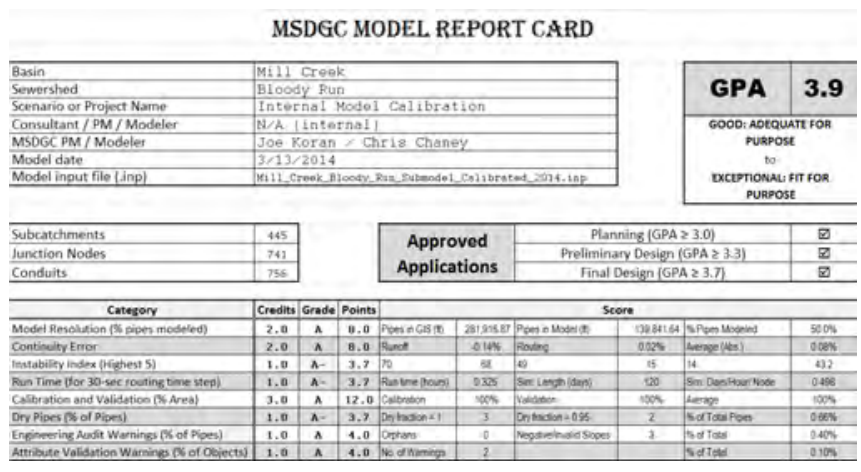

Figure 8 Bloody Run model report card.

The report card scores the model in the following eight categories:

1. Model resolution (\% pipes modeled);

2. Continuity error;

3. Instability index (highest 5);

4. Run time (for $30 \mathrm{~s}$ routing time step);

5. Calibration and validation ( $\%$ area);

6. Dry pipes (percentage of pipes);

7. Engineering audit warnings (percentage of pipes); and

8. Attribute validation warnings (percentage of objects). 
The report card uses the following grades, which are also used in the American Society of Civil Engineers (ASCE) infrastructure report card (ASCE 2015).

A Exceptional: fit for purpose;

B Good: adequate for purpose;

C Mediocre: requires attention;

D Poor: at risk; and

F Failing/critical: unfit for purpose.

In the GPA calculation, model categories were weighted using credits based on their importance. For example, model calibration and validation has 3 credits indicating it is 3 times more important than other 1 credit categories such as model instability and run time.

\section{Current Activities}

To comply with an aggressive consent decree schedule, MSD is performing many other model related activities not discussed in this paper. Examples include:

- RDIl modeling using alternative methods such as initial abstraction and SWMM aquifer module;

- RTC modeling;

water quality modeling;

. WWTP process modeling (Hydromantis GPS-X); update of modeling guidance and standards (alternative model C\&V approaches for continuous calibration);

- integrated watershed planning for SSO areas; and - consent decree project designs.

\section{Conclusions}

MSD's System Wide Model represents an extremely powerful and useful tool. In developing this tool, MSD has advanced the state of the art in collection system modeling in a number of areas including the simple size and scope of the model, the application of rain-radar data, and the use of water consumption data to estimate dry weather flows. The result of this effort is a new and valuable resource within MSD that leverages the agency's investment in GIS to provide benefits long into the future in support of MSD's mission. MSD's model is one of the largest SWMM models of the world. Maintaining a large model is not without challenges. Justifying endless model recalibration and revalidation has been the biggest challenge. MSD is developing new guidelines and model evaluation tools to tackle this challenge.

\section{References}

ASCE (American Society of Civil Engineers). 2015. 2013 Report Card for America's Infrastructure. Reston, VA: ASCE. www.infrastructurereportcard.org.

Box, G. E. P. and N. R. Draper. 1987. Empirical Model Building and Response Surfaces. New York: John Wiley \& Sons.

CDM. 2003. MSD System Wide Model: Executive Summary.

Hamilton County. 2015. "Cincinnati Area Geographic Information System (CAGIS)." cagismaps.hamilton-co.org/cagisportal

Huber, W. C. and R. E. Dickinson. 1988. Storm Water Management Model User's Manual Version 4. Athens, GA: U.S. Environmental Protection Agency. EPA/600/3-88/001A.

James, W. 2005. Rules for Responsible Modeling, 4th ed. Guelph: $\mathrm{CHI}$ Press.

Marsalek, J., T. M. Dick, P. E. Wisner and W. G. Clarke. 1975. "Comparative Evaluation of Three Urban Runoff Models." Water Resources Bulletin 11 (2): 306-28.

MSD. 2013. Modeling Guidelines and Standards: Volume 1 System Wide Model, Revision 3. Cincinnati, OH: Metropolitan Sewer District of Greater Cincinnati.

https://www.msdgc.org/downloads/customer_care/ forms_and_documents/modeling/modeling_guidelines_ and_standards.pdf.

Roesner, L. A., R. E. Dickinson and J. A. Aldrich. 1988. Storm Water Management Model User's Manual, Version 4, EXTRAN Addendum. Athens, GA: U.S. Environmental Protection Agency. EPA/600/3-88/001B.

Rossman, L. A., R. E. Dickinson, T. Schade, C. Chan, E. H. Burgess, D. Sullivan and D. Lai. 2004. "SWMM5: The Next Generation of EPA's Storm Water Management Model." Journal of Water Management Modeling 2004:R220-16. doi: 10.14796/JWMM.R220-16.

WaPUG (Wastewater Planning Users Group). 2002. Code of Practice for Hydraulic Modeling of Sewer Systems Version 3.001, November 2002, Amended December 2002. London: Wastewater Planning Users Group.

Wikiquote. 2015. "George E. P. Box." en.wikiquote.org/wiki/George_E._P._Box. 